\title{
High-Pressure Gel Loader for Capillary Array Electrophoresis Microchannel Plates
}

BioTechniques 31:1150-1154 (November 2001)

\author{
J.R. Scherer, B.M. Paegel, \\ G.J. Wedemayer, C.A. \\ Emrich, J. Lo, I.L. Medintz, \\ and R.A. Mathies \\ University of California \\ Berkeley, Berkeley, CA, USA
}

\section{INTRODUCTION}

The Human Genome Project has driven the development and commercial implementation of capillary array electrophoresis systems for high-throughput DNA analysis $(3,6)$. By miniaturizing capillary electrophoretic devices through microfabrication, significant benefits can be realized, such as smaller sample and reagent volumes, lower costs, higher assay speed, and increased throughput $(2,4,11)$. Rapid, high-quality genetic analysis and sequencing data have been obtained using a variety of microfabricated capillary electrophoresis systems $(1,2,4,11,18,20)$. The overall throughput can be increased by performing multiple analyses in parallel on high-density capillary array electrophoresis ( $\mu \mathrm{CAE})$ microplates $(7,16$, 17,21). There is significant interest in the commercial implementation of these devices for DNA genotyping and sequencing analysis $(1,2,4,11,15)$. Indeed, the first generation of commercial microfabricated electrophoretic devices are already being evaluated (14).

To implement these microfabricated platforms, supporting automation technology must be concomitantly developed for microfluidic sample handling (preparation and loading), gel loading, microchannel plate (MCP) washing, and data analysis. We recently described methods for the facile transport of $\mu \mathrm{CAE}$ data to a commercial genotyping analysis software platform (19). Here, we present the design and operation of an MCP gel-loading/washing system that effectively addresses an im portant additional need for implementing $\mu \mathrm{CAE}$ analysis. The gel loader is designed to force aqueous solutions, helium gas, or a variety of separation media through the arrays of microchannels in an MCP in a controlled and reproducible manner. Using this system, we can load the MCP with high-viscosity media such as linear polyacrylamide (LPA) for electrophoresis, and clean and dry the chips.

\section{MATERIALS AND METHODS}

Our microchannel plate design consists of 96 separation channels arrayed radially around a common central anode reservoir (Figure 1). Pairs of channels share a common waste and cathode reservoir (Figure 1A), and channels are grouped into four quadrants of 24 microchannels each (16). An advantage of this design is that all separation microchannels can be washed or loaded in parallel by addressing the central anode reservoir.

Figure 2 is a diagram of the MCP gel-loading/washing system. A photograph of the assembled loading module is shown in Figure 3. The wafer is supported on a cross bar, and a mechanically driven piston forces the MCP against the loading module. A series of valves in a manifold controls whether helium, water, or separation medium is delivered to the MCP.

\section{Device Construction}

The loading module was machined by the UC Berkeley Chemistry Machine Shop according to drawings provided at their Web site, www.cchem.berkeley. edu/ ramgrp/supplemental2/. The water 
reservoir is manufactured from a section of 4-in stainless steel pipe (wall thickness, $3 / 8$ in). The system is plumbed throughout with either $1 / 8$ - or $1 / 16$-in stainless steel tubing. High-pressure D Series non-rotating stem valves with 1/8-in Swagelok inlet and Kel-F outlet stem tips (Oakland Valve and Fitting, Concord, CA, USA) are used at the appropriate intersections (Figure 2, valve nos. 1-7 and 9). Valve no. 8 is a highpressure needle control valve.

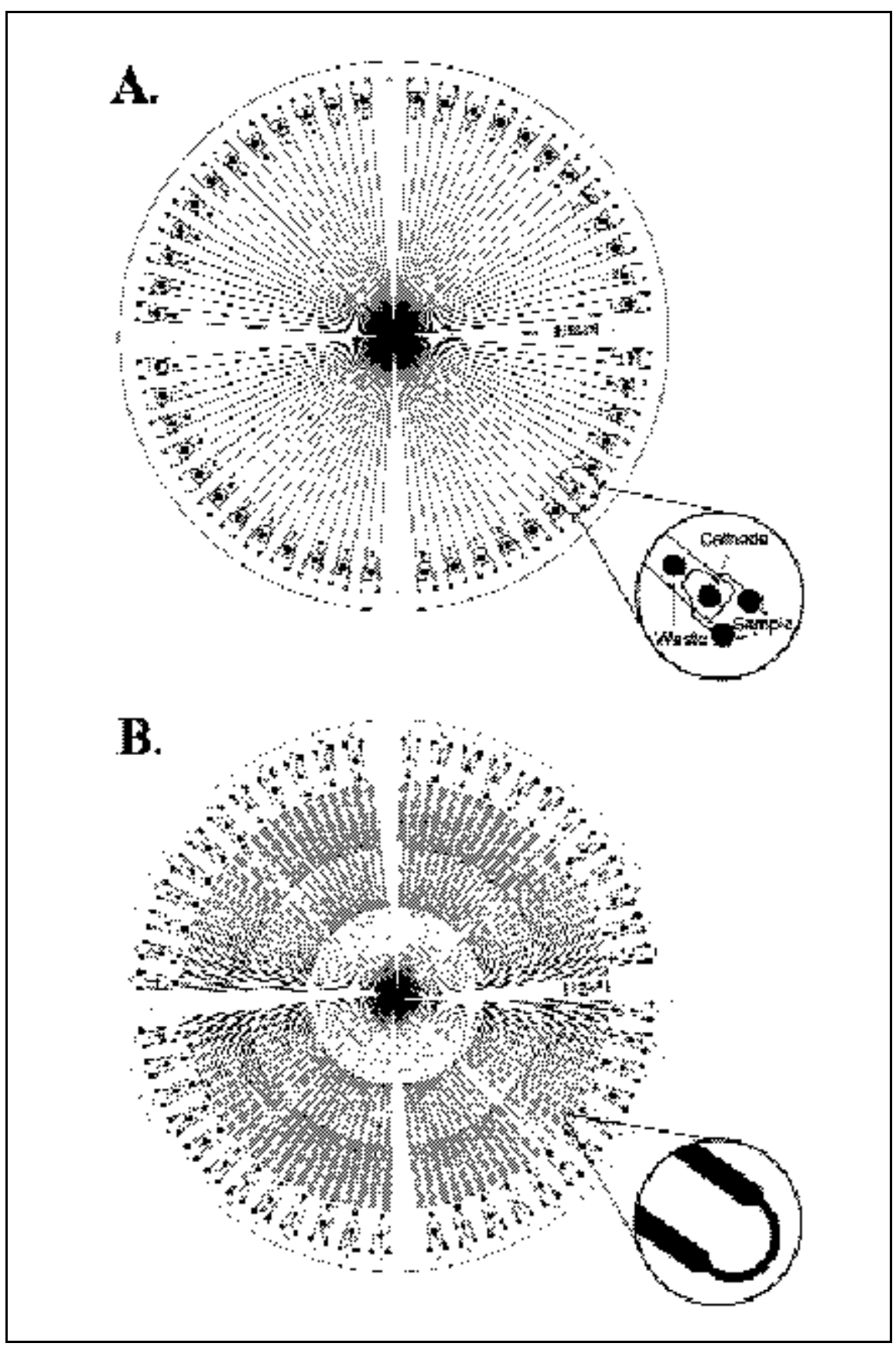

Figure 1. Design of the 96-channel capillary array electrophoresis microchannel plates. (A) Mask pattern used to form the straight-channel radial CAE MCP on a 150-mm diameter wafer. Each straight channel has an effective separation length of approximately $55 \mathrm{~mm}$. (B) Mask pattern used to form a 96channel folded-turn CAE MCP. These extended separation channels utilize tapered turns to increase the separation length to $16 \mathrm{~cm}$ without a loss of resolution (11). Microchannel dimensions range from 30-60 $\mu \mathrm{m}$ in depth and 120-200 $\mu \mathrm{m}$ in width. The straight-channel design is optimized for high-speed genotyping, while the folded-turn design is used for high-resolution separations such as DNA sequencing.
The loading module can be vented and removed for matrix replenishment or for cleaning with water. Closing the needle control valve no. 8 isolates the gel loader from the rest of the pressurized system (Figure 2). Valve no. 9 allows pressure relief in the gel loader so that the MCP may be removed. Similarly, valve nos. 4 and 7 isolate the water reservoir, opening valve no. 6 , then venting the water reservoir for refilling. The entire system is rated to $1000 \mathrm{psi}$, and a 1000-psi relief valve is attached to the helium regulator.

The loading modules are fabricated from poly-methyl methacrylate (Figure 2B). The reservoir capacity is approximately $1 \mathrm{~mL}$. A cover plate can be screwed to the bottom of the module, which allows centrifugation at $110 \times g$ to remove bubbles from the gel. The cover plate is removed, and the loading module is placed into the loader for filling the MCP with matrix. A no. 006 O-ring near the exit port seals the reservoir to either the cover plate or the MCP. A larger O-ring seals the top of the loading module to the aluminum cross bar.

The loader accommodates 100-, 150-, and 200-mm diameter MCPs. The MCP is supported on a platform with a hollow central shaft. An adjustable clamp (Straight line 601 clamp; Destaco, Birmingham, MI, USA) raises a piston with a protective elastomer cover in the central hollow shaft against the MCP, loading module, and cross bar assembly. The clamp is manually adjusted to deliver the correct amount of pressure to prevent the leakage of medium.

\section{Device Operation}

Gel matrix is loaded into the microchannels uniformly by $(i)$ filling the loading module with approximately 1 $\mathrm{mL}$ gel and placing it on top of the MCP, (ii) clamping the MCP between the adjustable piston and the loading module, and (iii) pressurizing the system with helium. A typical gel-loading pressure for straight-channel MCPs is approximately $300 \mathrm{psi}$, and the uniform loading of all microchannels with $3 \%$ LPA takes between 5-10 s. Approximately $150 \mu \mathrm{L}$ gel is pumped through the chip to fill all of the channels. All channels fill at approximately the same rate. The pressure is relieved when visu- 
al inspection determines that all of the channels are filled. The needle control valve no. 8 regulates pressurized delivery. Replacing the module with an empty one and switching the valves allows us to wash the MCP with water and then with helium. Helium is used for pressurizing the matrix because of its low gas solubility, which minimizes subsequent bubble formation after relieving the pressure. Cleaning the microchannels with water and drying them with helium requires approximately $5 \mathrm{~min}$ at 400 psi. For washing, we tip the loading module on its side and let the runoff drain into a waste basin.

The longer folded-channel microchips (Figure 1B), which utilize tapered turns and a higher LPA concentration (approximately 4\%-5\%) for DNA sequencing analyses, require higher pressure and longer loading times. About 5 min are required to load $400 \mu \mathrm{L} 4.7 \%$ LPA matrix at approximately 600 psi, and cleaning/drying takes about $10 \mathrm{~min}$ at the same pressure. These foldedchannel chips are first filled with buffer and then immediately loaded with gel media. This buffer pre-filling facilitates the loading of higher viscosity media by pre-wetting the channels. Excess gel in the circular wells is removed using a micropipette tip attached to a vacuum line.

All MCPs are fabricated from two thermally bonded glass wafers. These MCPs can withstand high (approximately 2000 psi) compressive stress. The compatibility of this loader design with MCPs fabricated from more fragile materials [e.g., polycarbonate, poly (methyl methacrylate)] has not been determined.

\section{RESULTS AND DISCUSSION}

Commercial CAE devices such as the MegaBACE-1000 (Amersham Pharmacia Biotech, Piscataway, NJ, USA) and the ABI PRISM ${ }^{\circledR} 3700$ DNA Analyzer (Applied Biosystems, Foster City, CA, USA) use integrated pressure loading systems for automated gel matrix replacement and capillary cleaning (11). To make the $\mu \mathrm{CAE}$ platform similarly useful for high-throughput sequencing and genotyping, we have developed a convenient, automated washing and gel-loading system. The
MCP loader has been successfully used in a number of genotyping and sequencing investigations $(8-10,13)$. Different media have been loaded and cleaned from the chips including

$0.75 \%-3.0 \%$ hydroxyethylcellulose $(n$ $=100-1000 \mathrm{cp})$ and LPA up to $4.8 \%(n$ $=$ approximately $10000-100000 \mathrm{cp}$ ).

Additionally, we have found the gel loader to be helpful for delivering

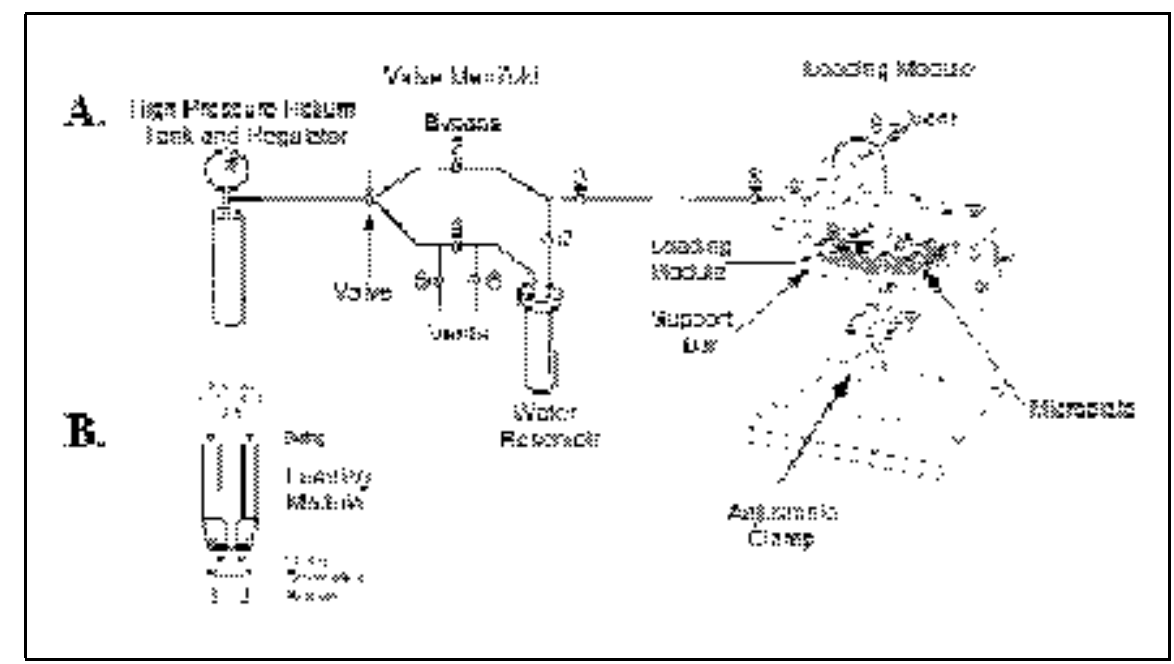

Figure 2. System schematic. (A) The MCP gel loader/washer with a wafer in place. The numbers indicate the placement and the order of the valves. (B) Expanded view of the gel reservoir detailing the detachable cover plate that allows centrifugation of the separation media before loading. Engineering diagrams are available at www.cchem.berkeley.edu/ ramgrp/supplemental2/.

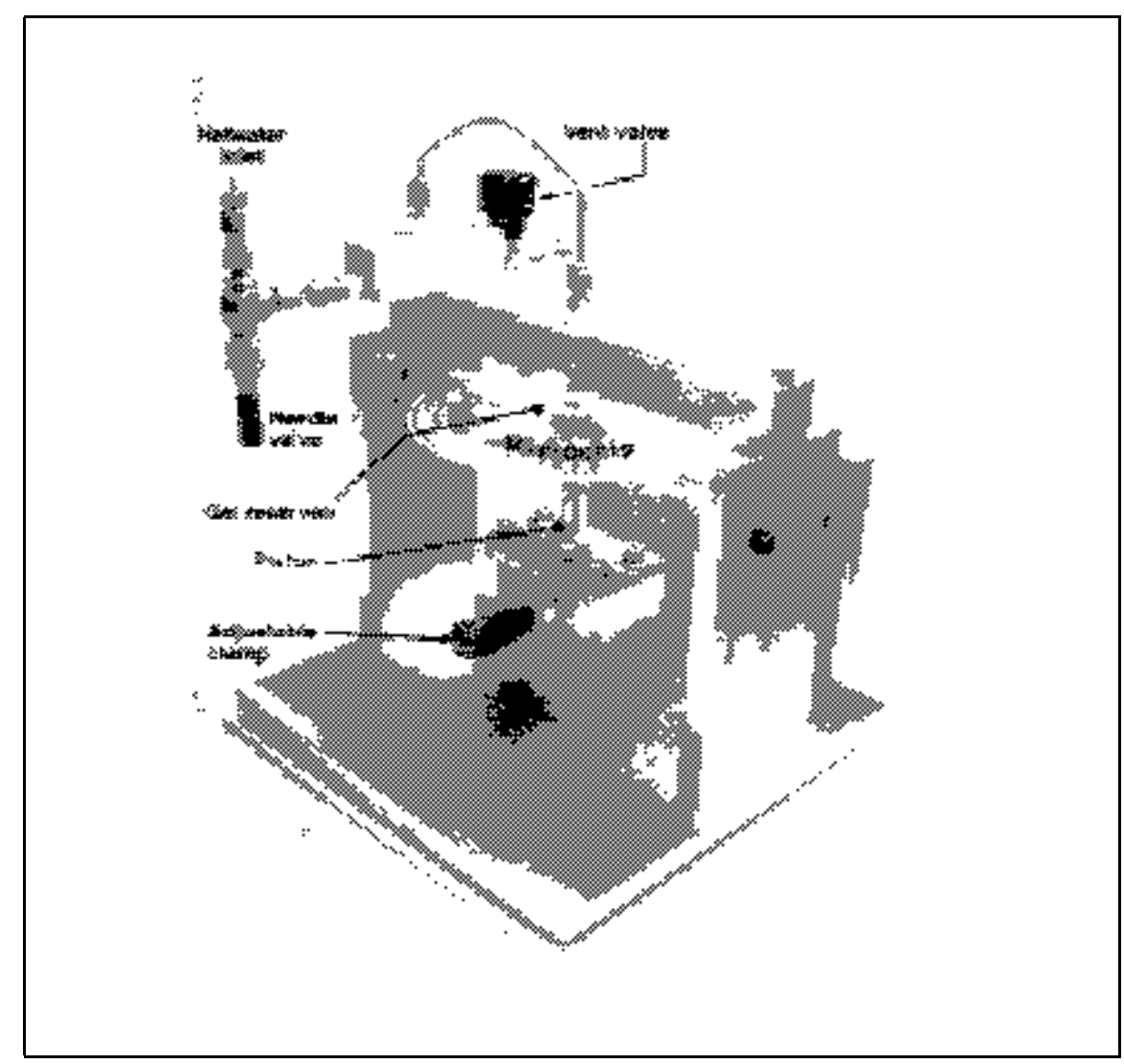

Figure 3. Photograph of the gel loader with a 150-mm MCP in place on the support bar. 
chemical solutions to the microplate and for washing/drying during the surface coating process (5). The use of this technology is not limited to radial $\mu \mathrm{CAE}$ formats. Other $\mu \mathrm{CAE}$ designs can be accommodated through the use of a custom delivery manifold and platform that would direct media into the appropriate common reservoirs. Along with this washing and loading device, we have developed and implemented supporting robotic technology for independent sample loading and efficient data analysis programs (19). The entire process from empty chip to 50000 called DNA sequencing bases requires approximately $40 \mathrm{~min}$. The gel loader described here is a step toward the assembly of a completely integrated highthroughput $\mu \mathrm{CAE}$ analysis platform that will become the next-generation electrophoretic genetic analysis system.

\section{ACKNOWLEDGMENTS}

This research was supported by NIH grant no. HG01399, NIH Program Project grant no. P01 CA77664 with Johns Hopkins University, and by the Director, Office of Science, Office of Biological and Environmental Research of the U.S. Department of Energy under contract no. DE FG91ER61125 (R.A.M.). MCP fabrication was performed at the U.C. Berkeley Microfabrication Laboratory.

\section{REFERENCES}

1.Backhouse, C., M. Caamano, F. Oaks, E. Nordman, A. Carrillo, B. Johnson, and S. Bay. 2000. DNA sequencing in a monolithic microchannel device. Electrophoresis 2 1:150156.

2.Carrilho, E. 2000. DNA sequencing by capillary array electrophoresis and microfabricated array systems. Electrophoresis 21:55-65.

3.Collins, F.S., A. Patrinos, E. Jordan, A. Chakravarti, R. Gesteland, L. Waters, E. Fearon, L. Hartwell et al. 1998. New goals for the US Human Genome Project: 19982003. Science 282:682-689.

4.Dolnik, V., S.R. Liu, and S. Jovanovich. 2000. Capillary electrophoresis on microchip. Electrophoresis 21:41-54.

5.Hjerten, S. 1985. High-performance electrophoresis-elimination of electroendosmosis and solute adsorption. J. Chromatogr. 347:191-198.

6.Kheterpal, I. and R.A. Mathies. 1999. Capillary array electrophoresis DNA sequencing. Anal. Chem. 71:31A-37A.

7.Liu, S., H. Ren, Q. Gao, D.L. Roach, R.T. Loder, T.M. Armstrong, Q. Mao, I. Blaga et al. 2000. Automated parallel DNA sequencing on multiple channel microchips. Proc. Natl. Acad. Sci. USA 97:5369-5374.

8.Medintz, I., L. Berti, C.A. Emrich, J. Tom, J.R. Scherer, and R.A. Mathies. 2001. Genotyping energy-transfer-cassette-labeled short-tandem-repeat amplicons with capillary array electrophoresis microchannel plates. Clin. Chem. 47:1614-1621.

9.Medintz, I., W.W. Wong, L. Berti, L. Shiow, J. Tom, J. Scherer, G. Sensabaugh, and R.A. Mathies. 2001. High performance multiplex SNP analysis of three hemochromatosis-related mutations with capillary array electrophoresis microplates. Genome Res. $11: 413-421$.

10.Medintz, I.L., B.M. Paegel, and R.A. Mathies. 2001. Microfabricated capillary array electrophoresis DNA analysis devices. J. Chromatogr. A 924:265-270.

11.Meldrum, D. 2000. Automation for genomics, part two: sequencers, microarrays, and future trends. Genome Res. 10:1288-1303.

12.Paegel, B.M., L.D. Hutt, P.C. Simpson, and R.A. Mathies. 2000. Turn geometry for minimizing band broadening in microfabricated capillary electrophoresis channels. Anal. Chem. 72:3030-3037.
13.Paegel, B.P., C.A. Emrich, G.J. Wedemayer, J.R. Scherer, and R.A. Mathies. 2001. Highthroughput DNA sequencing in a 96-lane microfabricated electrophoresis device. Manuscript in Preparation.

14.Panaro, N.J., P.K. Yuen, T. Sakazume, P. Fortina, L.J. Kricka, and P. Wilding. 2000. Evaluation of DNA fragment sizing and quantification by the Agilent 2100 Bioanalyzer. Clin. Chem. 46:1851-1853.

15.Sanders, G.H.W. and A. Manz. 2000. Chipbased microsystems for genomic and proteomic analysis. Trends Anal. Chem. 19:364378.

16.Shi, Y.N., P.C. Simpson, J.R. Scherer, D. Wexler, C. Skibola, M.T. Smith, and R.A. Mathies. 1999. Radial capillary array electrophoresis microplate and scanner for highperformance nucleic acid analysis. Anal. Chem. 71:5354-5361.

17.Simpson, P.C., D. Roach, A.T. Woolley, T. Thorsen, R. Johnston, G.F. Sensabaugh, and R.A. Mathies. 1998. High-throughput genetic analysis using microfabricated 96sample capillary array electrophoresis microplates. Proc. Natl. Acad. Sci. USA 95:2256-2261.

18.Syvanen, A.C. 1999. From gels to chips: "Minisequencing" primer extension for analysis of point mutations and single nucleotide polymorphisms. Hum. Mutat. 13:1-10.

19.Wedemayer, G.J., I. Medintz, W.W. Wong, J.R. Scherer, and R.A. Mathies. 2001. Conversion of capillary electrophoresis microchip genotyping data for analysis with Genetic Profiler ${ }^{\mathrm{TM}}$ software. BioTechniques 30:122-128.

20.Woolley, A.T. and R.A. Mathies. 1994. Ultra-high-speed DNA fragment separations using microfabricated capillary array electrophoresis chips. Proc. Natl. Acad. Sci. USA 24:11348-11352.

21.Woolley, A.T., G.F. Sensabaugh, and R.A. Mathies. 1997. High-speed DNA genotyping using microfabricated capillary array electrophoresis chips. Anal. Chem. 69:2181-2186.

Received 26 March 2001; accepted 5 June 2001.

Address correspondence to:

Richard A. Mathies

307 Lewis Hall

Department of Chemistry

University of California

Berkeley, CA 94720, USA

e-mail: rich@zinc.cchem.berkeley.edu

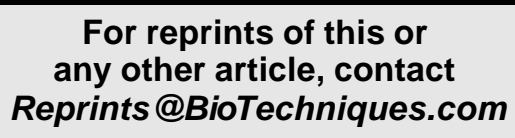

